\title{
Rehabilitation of a Patient with Immediate Complete Denture
}

\author{
1Jyoti B Nadgere, ${ }^{2}$ Suyog Kisanrao Masram, ${ }^{3}$ Sabita M Ram, ${ }^{4}$ Naisargi P Shah
}

\begin{abstract}
Patient's desire to have a replacement with complete dentures before losing all their natural teeth, this is important for the psychology of the patient. Patients with gross mobility of the teeth needing replacement with complete denture without going through a period of edentulousness has become mandatory for a prosthodontist to treat. An immediate denture is a treatment of choice for such patients. A case report is being presented for a patient with flared, prominent, mobile anterior teeth treated with a successful immediate denture.
\end{abstract}

Keywords: Immediate complete denture, Interim prosthesis.

How to cite this article: Nadgere JB, Masram SK, Ram SM, Shah NP. Rehabilitation of a Patient with Immediate Complete Denture. J Contemp Dent 2016;6(1):90-95.

Source of support: Nil

Conflicts of interest: None

\section{INTRODUCTION}

Immediate denture is a complete or removable partial denture fabricated for insertion immediately following the removal of natural teeth. From patient's perceptions, it is better to have the teeth be replaced immediately after extraction for psychological reason and for being socially accepted. The advantage of an immediate denture is that it maintains patient's appearance, as there is no edentulous period. It also maintains the vertical dimension of occlusion, facial height, muscle tone, and tongue position. Anterior teeth size, form, and shade can be accurately replicated. Also, speech and mastication are not compromised and nutrition can be

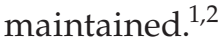

A well-made immediate complete denture acts as a splint over the surgical site and protects the wound against the injury of food and opposing teeth. ${ }^{2}$ Therefore, there is less postoperative pain. The drawback of an immediate denture is that the final esthetic results may be questionable due to the inability to take an anterior

\footnotetext{
${ }^{1,4}$ Professor, ${ }^{2}$ Postgraduate Student (3rd Year), ${ }^{3}$ Dean Professor and Head

${ }^{1-4}$ Department of Prosthodontics, Crown and Bridge, MGM Dental College and Hospital, Navi Mumbai, Maharashtra, India

Corresponding Author: Jyoti B Nadgere, Professor Department of Prosthodontics, Crown and Bridge, MGM Dental College and Hospital, Navi Mumbai, Maharashtra, India, Phone: 02227436604, e-mail: jyotinadgere@gmail.com
}

try-in. Also, the retention and stability may not be as good as that of the conventional complete denture. ${ }^{2-4}$ It is due to these technical difficulties that immediate complete dentures are considered as an Interim prosthesis. ${ }^{1}$ They may require relining or a new set of dentures may need to be fabricated within a short period of time. However, tissue conditioners may be useful in such cases. ${ }^{1}$

A case report is being presented for a patient with flared, prominent, mobile anterior teeth treated with a successful immediate denture.

\section{CASE REPORT}

A 31-year-old female patient reported to the Department of Prosthodontics with the chief complaint of pain and inability to chew food due to mobility of teeth. She was unhappy because of proclined anterior teeth. On extraoral examination, the patient had a small face with prominent, proclined, long flaring anterior teeth. This caused incompetency of the lips (Fig. 1). Intraoral examination showed spacing due to flaring of the anterior teeth (Fig. 2). She had a deep maxillary palatal vault (Fig. 3) and crowding with teeth in mandibular arch (Fig. 4). Generalized grade II mobility and class III recession was present with teeth in both maxillary and

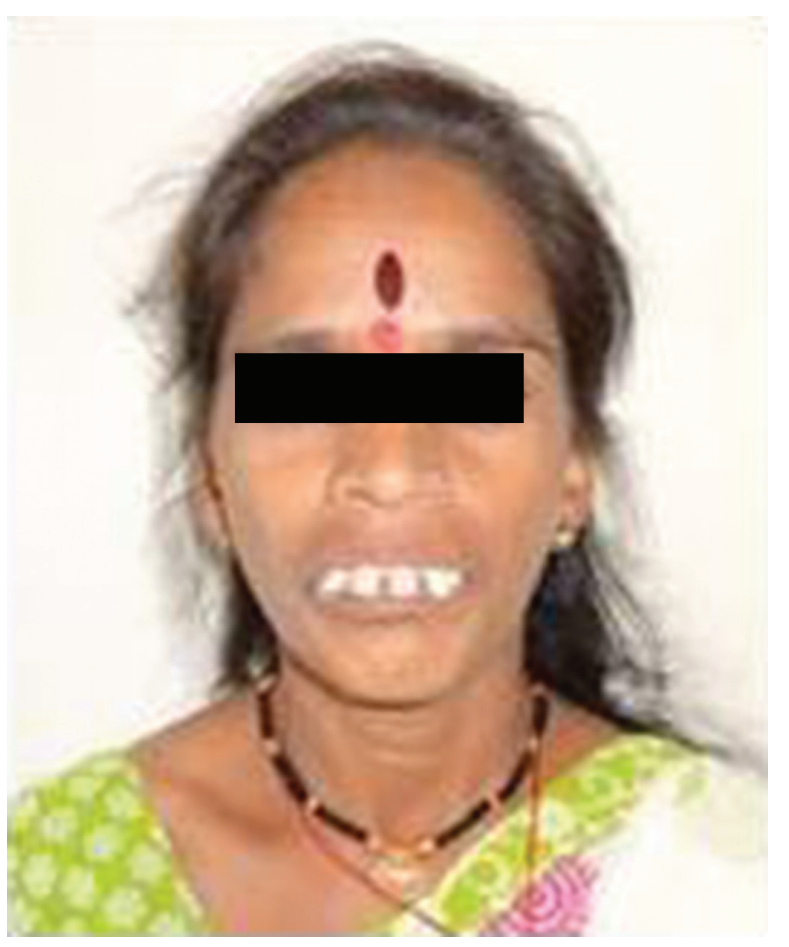

Fig. 1: Preoperative extraoral 


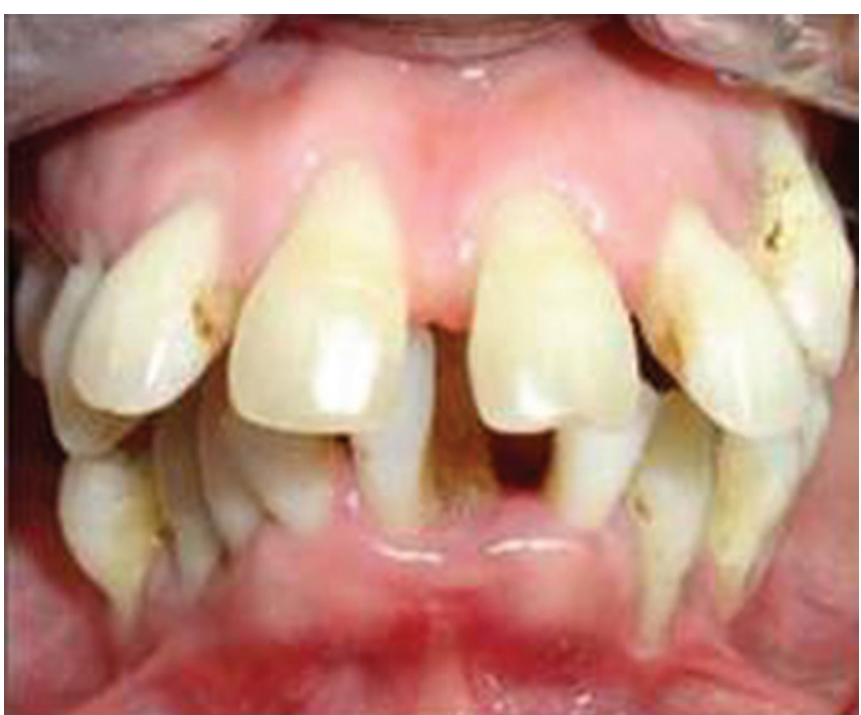

Fig. 2: Preoperative intraoral showing prominent premaxilla with proclined anteriors

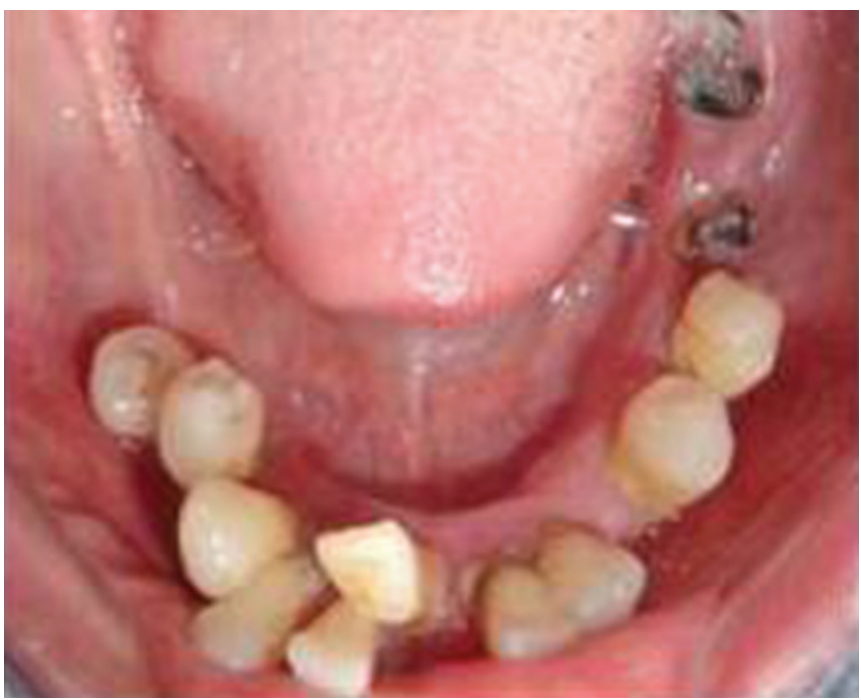

Fig. 4: Preoperative intraoral showing crowding in mandibular teeth and root stumps with 36 and 37

mandibular arches. Root stumps were present with 16 , 27,36 , and 37. On radiological examination, severe bone loss was seen in relation with all the teeth (Fig. 5).

The patient's teeth were not in a condition to be saved. Therefore, it was planned to extract all the teeth, but to prevent the patient from being edentulous, immediate complete dentures for maxillary and mandibular arches were planned. The following step-by-step procedure was followed for the entire treatment plan.

\section{Diagnostic Impressions}

Tooth and tissue undercuts were blocked in the patient's mouth with carding wax to prevent the interlocking of the impression material and diagnostic impressions of upper and lower arches were made in stock metal trays with irreversible hydrocolloid impression material.

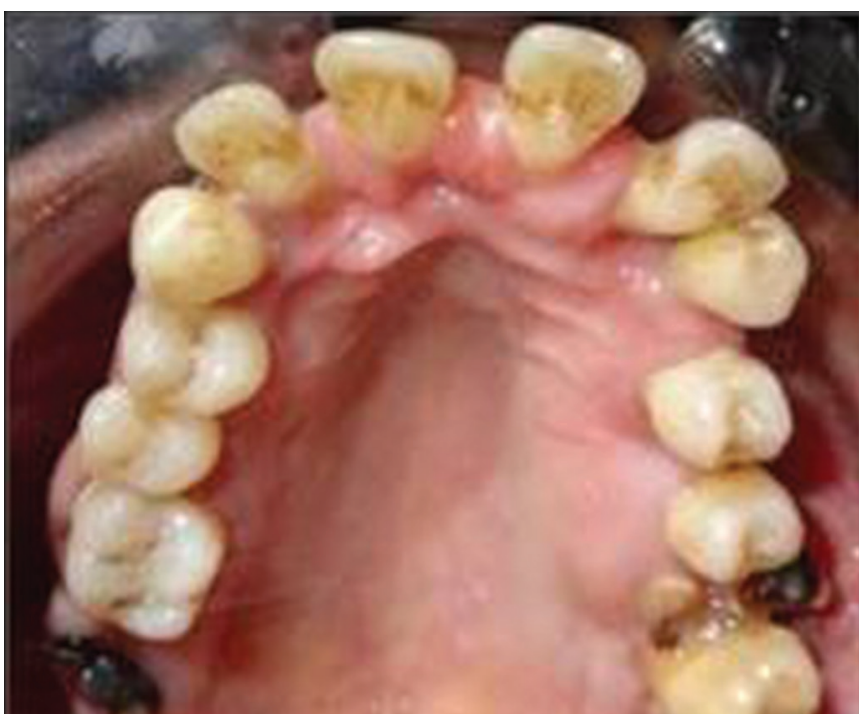

Fig. 3: Preoperative intraoral showing deep palatal vault with 17,26 root stumps

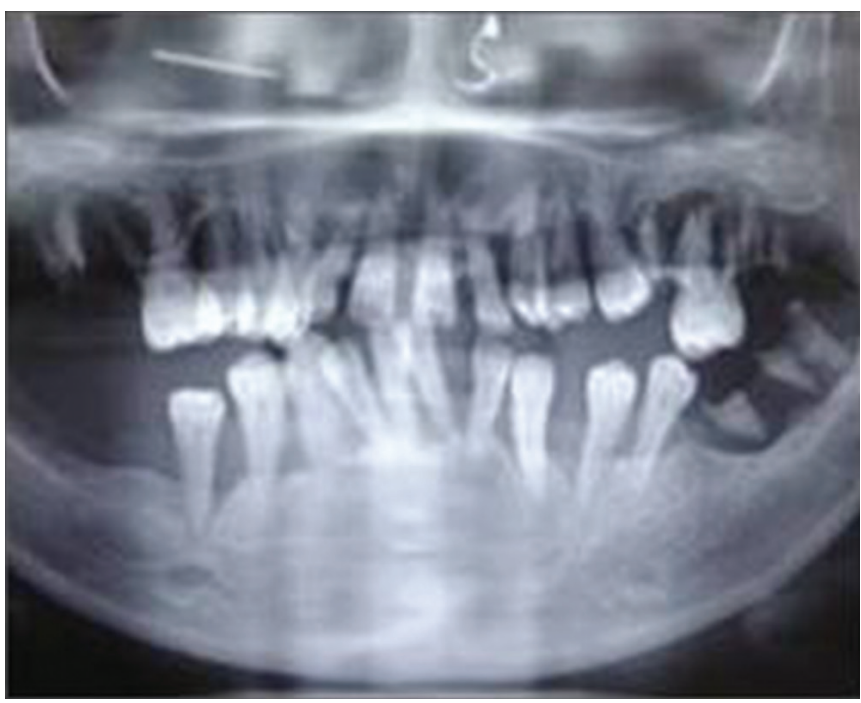

Fig. 5: Orthopantomography

Care was taken to prevent the teeth on the cast from breaking by placing metal pins in places of the teeth in impression and casts were poured with dental stone and mounted on articulator for diagnostic purpose. Casts were evaluated and decision was made to fabricate an immediate complete denture.

The posterior teeth were extracted with minimum trauma for preservation of bone, sutures were given, and hemostasis was achieved. She was advised to continue medications and postextractions instructions were given to her. Patient was recalled after 7 to 10 days for assessment of healing of the posterior ridges. ${ }^{1}$

\section{Final Impressions}

Primary impressions of both the maxillary and mandibular arches were made with irreversible hydrocolloid, poured 
with dental stone, and casts were obtained. Special trays were fabricated on the casts with adequate relief on the anterior teeth for the irreversible hydrocolloid. Border molding was carried out with low fusing impression compound and final impressions were made with irreversible hydrocolloid impression material (Figs 6 and 7). Impressions were poured in dental stone and casts were obtained. ${ }^{1,3,4}$

\section{Jaw-relation Record}

Temporary denture bases were adapted with shellac base plate on the casts; wax rims were made and kept ready for jaw relation. Vertical dimension was determined by Niswonger's method and the centric relation record was made following the static check bite method. A facebow record was taken to orient the maxillary cast on the articulator. The casts were mounted on the articulator. ${ }^{1,4,5}$

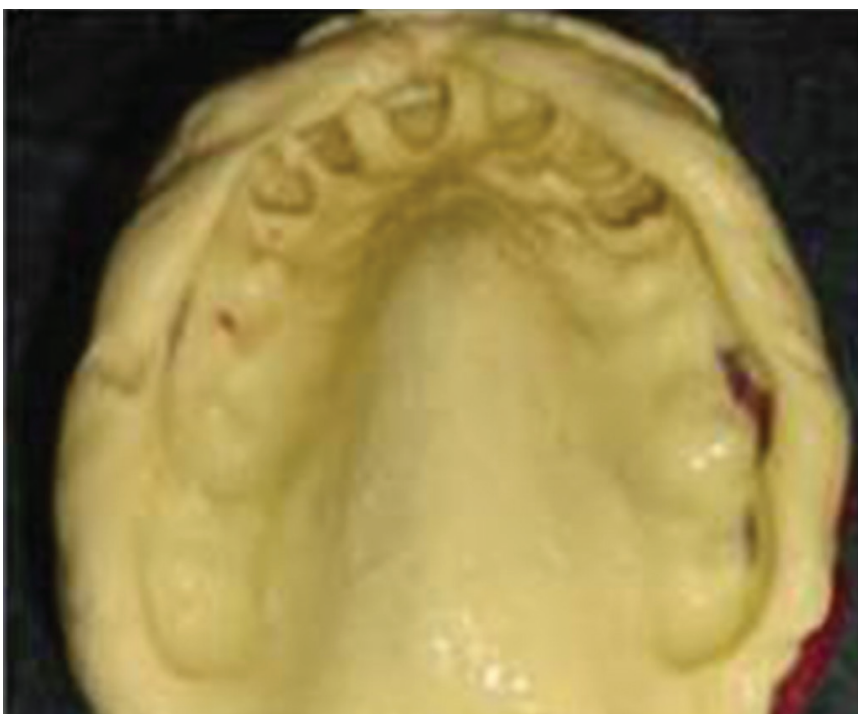

Fig. 6: Maxillary final impression

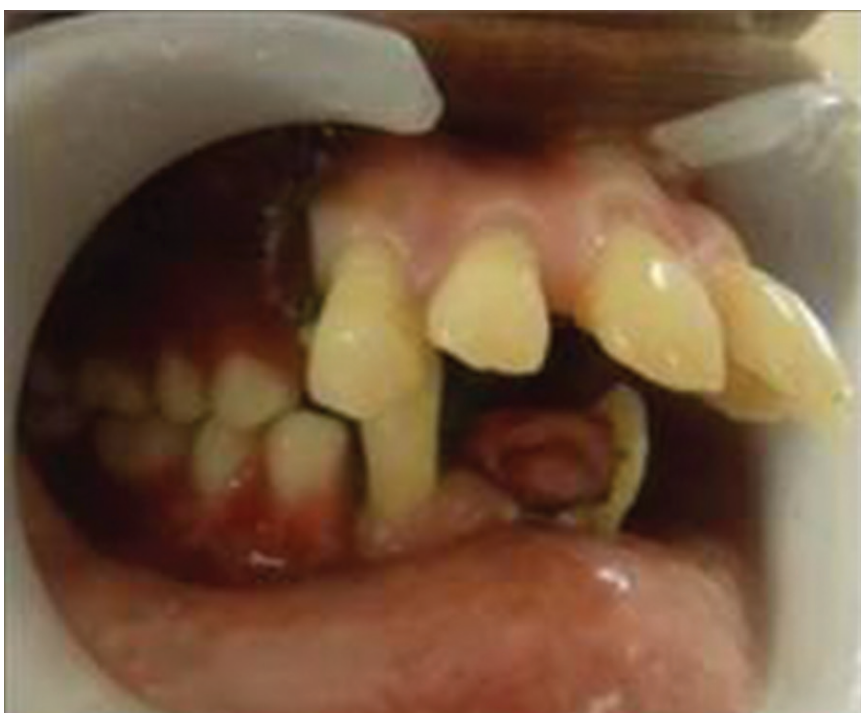

Fig. 8: Posterior try-in right side

\section{TEETH SELECTION AND ARRANGEMENT OF POSTERIOR TEETH}

Semi-anatomic crossed linked acrylic teeth narrower than the existing teeth were selected to avoid pressure on the posterior ridges. Teeth were arranged to provide multiple bilateral posterior contacts in centric relation.

\section{Posterior Try-in}

Denture adhesive was used for proper adaptation of denture bases for errorless try-in. The posterior try-in was taken to verify the correct vertical and centric relation records and comfort of the dentures was also checked (Figs 8 and 9). Patient was shown the try-in and informed that the anterior try-in would not be possible due to the presence of the anterior teeth.

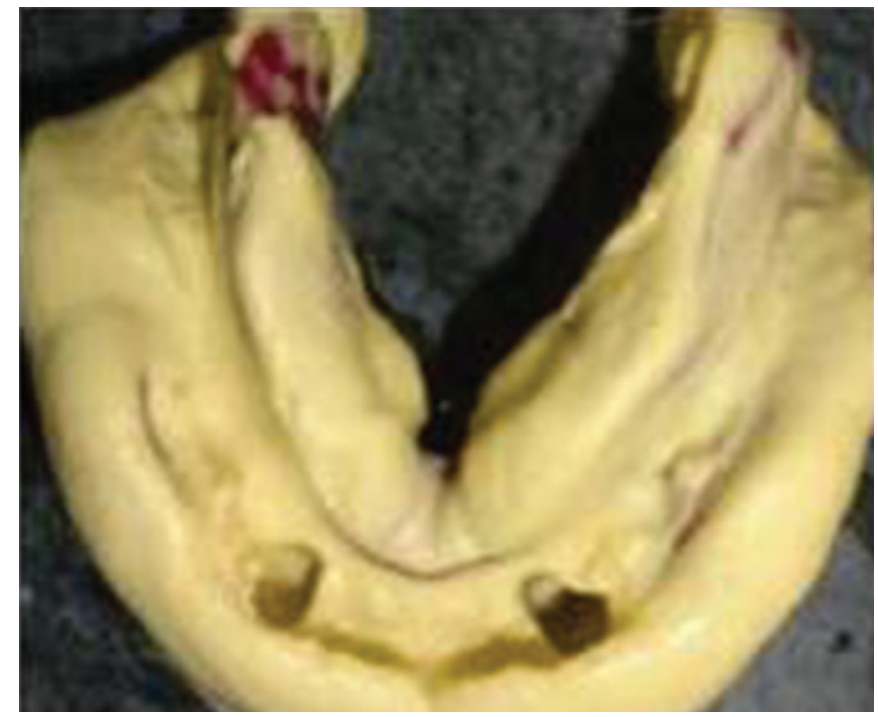

Fig. 7: Mandibular final impression

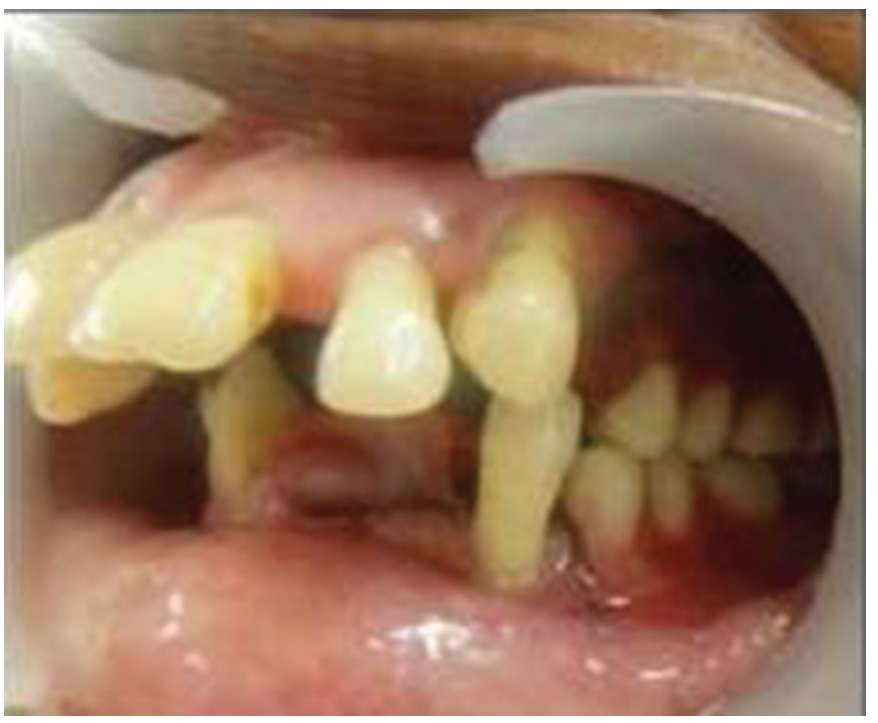

Fig. 9: Posterior try-in left side 


\section{SELECTION AND ARRANGEMENT OF ANTERIOR TEETH}

The existing teeth were unesthetic in appearance and disproportionate with the face of patient. The anterior teeth were selected to suit the patient's age sex and personality. As the anterior teeth required to be repositioned, the teeth were scrapped from the cast on one side of the arch and gross reduction of the cast was done to recontour the anterior ridge (Fig. 10). Teeth were arranged on one side, and later, the same procedure was carried out on the other side to complete the anterior arrangement (Fig. 11). Wax up was done for both upper and lower arches. The waxed-up dentures were removed from the cast; alginate impressions of both the upper and lower casts were made, poured in dental stone, and casts were obtained. Surgical templates were fabricated on these casts with vacuum form sheet for the surgical procedures (Fig. 12). The waxed-up denture were placed

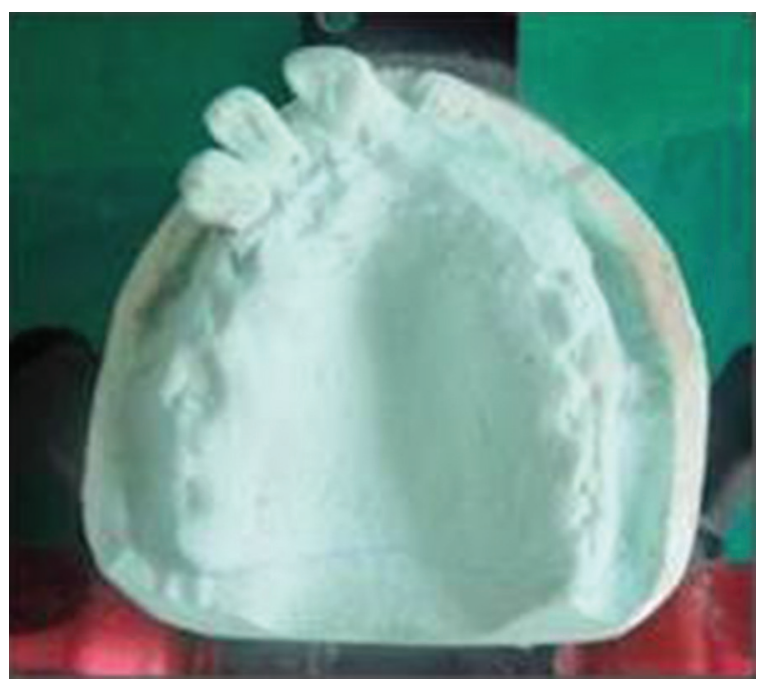

Fig. 10: Scrapping of anterior teeth on cast

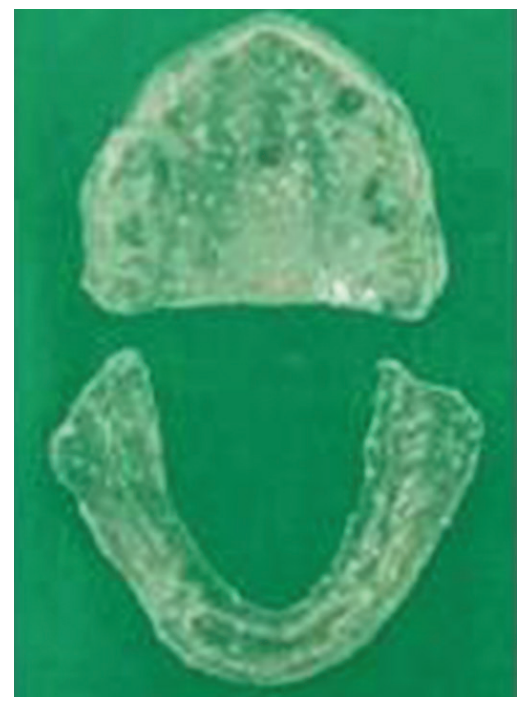

Fig. 12: Surgical templates back and sealed on the casts. Flasking, packing, and curing was done in the conventional manner. After proper finishing and polishing, dentures were stored in germicidal solution of $0.2 \%$ chlorhexidine and thoroughly rinsed with water prior to insertion. ${ }^{6}$

\section{Denture Insertion Procedures}

Presurgical medications were prescribed to patient 1 day prior to surgery. Early appointment was given and she was prepared for the surgery. Adequate local anesthesia was given and the maxillary anterior teeth were removed with minimum trauma. The clear surgical template was used during surgery for evaluation of the prepared surgical site and sutures were given (Fig. 13). The same procedure was also repeated for mandibular arch. After the surgical procedure was completed, the dentures were placed one at a time and evaluated for in retention and stability. After placing both the dentures, occlusion was checked and interferences were removed

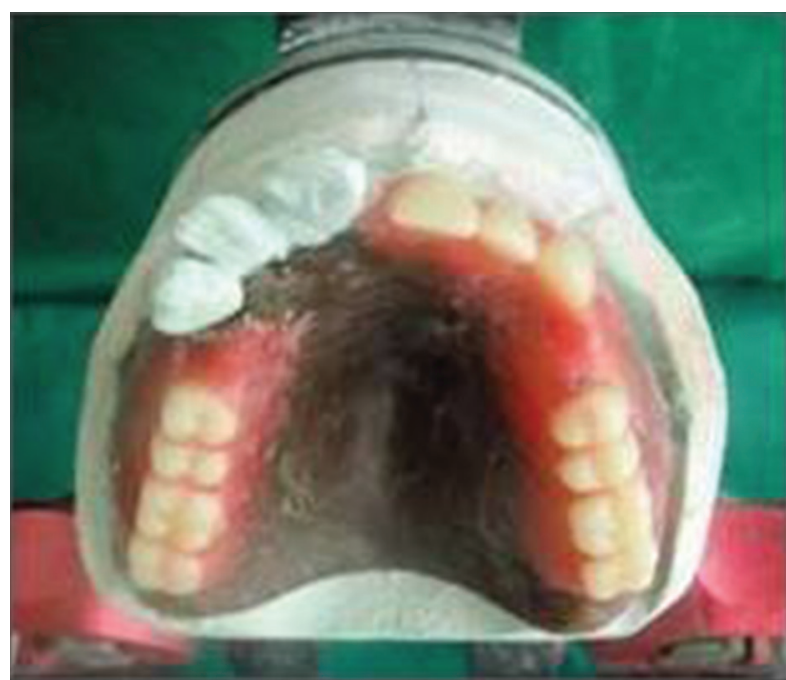

Fig. 11: Arrangement of anterior teeth

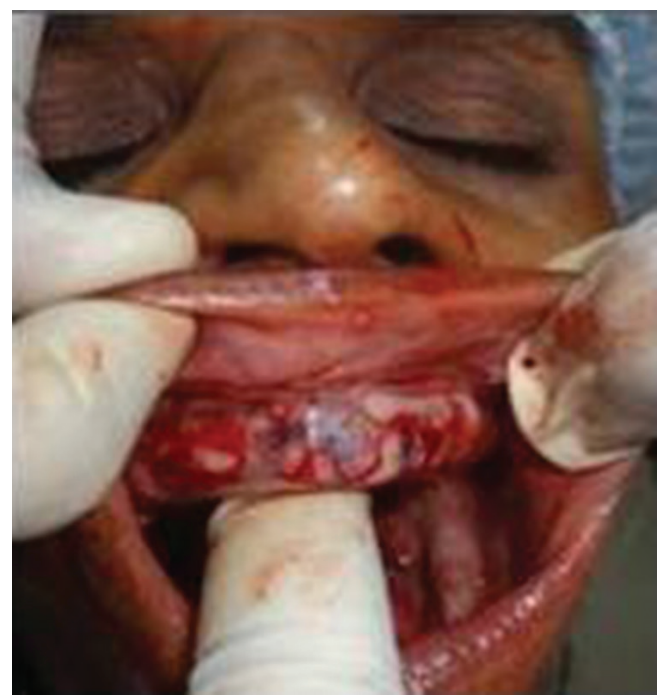

Fig. 13: Placement of surgical template after extraction of teeth 


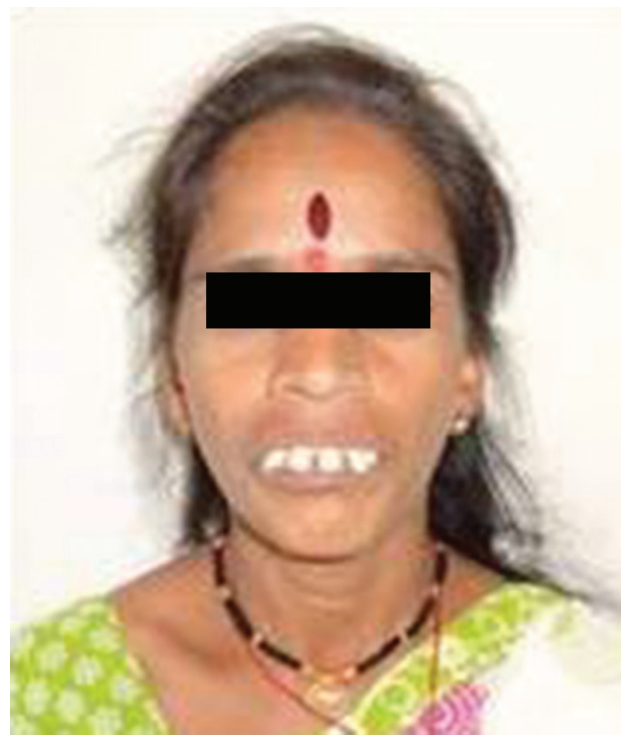

Fig. 14: Preoperative

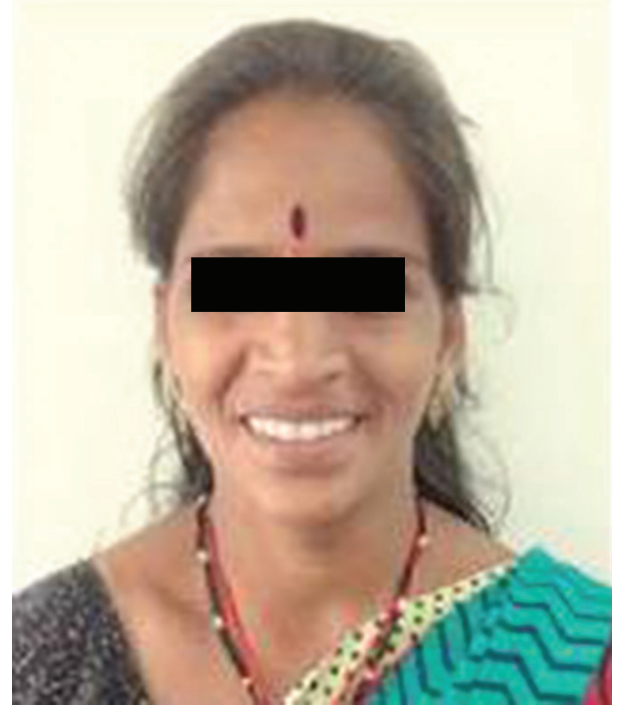

Fig. 16: Postoperative after conventional complete denture insertion

by selective grinding. The tissue conditioner was used for upper denture for better retention, as the gross amount of bone was reduced in the maxillary anterior region. 1,5,6

\section{Postinsertion Care}

The postoperative instructions were given to the patient. The patient was advised to apply cold packs for the next 1 hour. She was told to wear the denture for the next 24 hours without removing it and avoid expectoration. She was also advised to take liquid diet till the next appointment and to continue the medications. Patient was recalled after 24 hours; dentures were removed, cleaned, and kept in $0.2 \%$ chlorhexidine. The tissues were evaluated for any irritation and pain; required modifications in the denture were carried out. Tissue

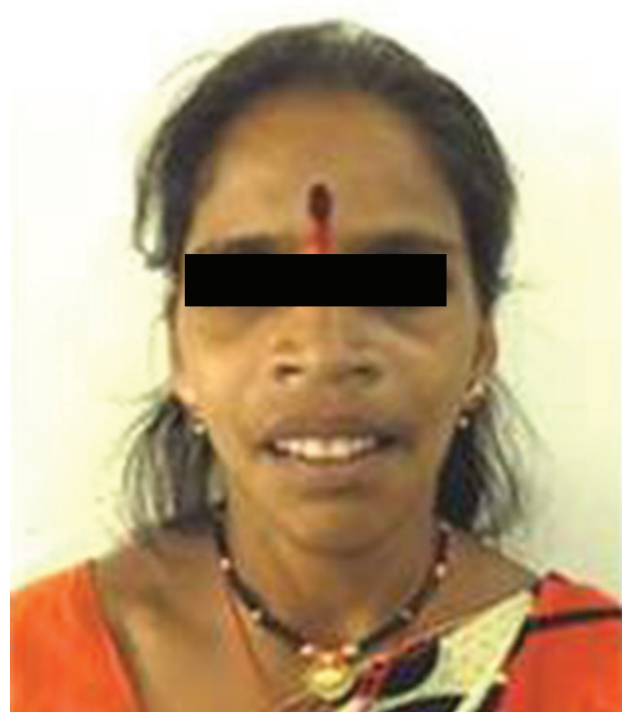

Fig. 15: Postoperative after immediate denture insertion

surfaces of the oral cavity were irrigated with $0.2 \%$ chlorhexidine mouthwash. Instruction was given to the patient to remove the dentures as minimum number of times as possible for the next 48 hours. The patient was instructed to clean the denture at each meal. She was also instructed to wear the denture at night for 3 days. After 1 week, the patient was recalled and the suture was removed. Patient was kept under regular follow-up. After 4 months, the patient was recalled for evaluation. Dentures were having poor retention; therefore, it was decided to fabricate a new set of complete denture. ${ }^{1,2,6-8}$ Astringent gum massage was prescribed to the patient for toughening of the tissues. When all soft and hard tissues were in healthy condition, the procedure for conventional complete denture was started and a new set of upper and lower denture was fabricated. The dentures were inserted in patient's mouth and checked for retention, stability, comfort, and occlusion. Patient was happy and satisfied with the outcome of the denture.

\section{DISCUSSION}

A young female patient requiring immediate replacement of all her teeth without going through the period of edentulousness; an immediate complete denture was planned and fabricated for fulfilling patient's desire and need. Patient was already explained that the immediate complete denture is considered as an interim prosthesis and should be relined or possibly a new set of dentures may be required to be fabricated within 6 months.

While fabricating the immediate denture, excess treaming of the cast was required to be carried out, as the teeth were severely proclined. The surgical templates acted as a guide for the surgeon to recontour the bone during extraction of teeth. 
Optimal retention, support, and stability for any removable prosthesis are important factors in treatment, success, and patient's comfort. ${ }^{2}$ Four months later, patients' complains of poor retention were addressed while fabricating a new set of dentures. Being one of the most important disadvantages of unpredictable esthetics as there was no try-in, the denture esthetics was not as good as that was expected. In addition to that as healing progressed, there was lack of adaptation, retention, and stability of the denture. Patient felt uncomfortable and was unhappy with the outcome of denture. Therefore, the decision was made to fabricate a definitive conventional complete denture. ${ }^{1,2,6-8}$ The patient was advised astringent gum massage for tissue toughening. When all soft and hard tissues were in a healthy condition, the procedures for conventional complete denture were started and a new set of maxillary and mandibular complete dentures was fabricated in a conventional manner. Patient was happy with the final outcome of dentures.

Immediate denture is a good option for the patient facing the edentulous state that provides restoration of esthetics, phonetics, and masticatory function. The patient did not have to endure a long healing process without teeth; it also facilitates the transition to the edentulous state. Proper follow-up care is essential for the success of an immediate denture.

\section{CONCLUSION}

An immediate complete denture in this case has not only achieved good esthetics but also improved functions within the physiologic limit of the tissues. An immediate complete denture is a treatment option for the patient who seeks for complete teeth to be replaced but not willing to go for complete edentulousness.

\section{REFERENCES}

1. Massad JJ, Cagna DR. Immediate complete denture impressions-case report and modern clinical technique. Dent Today 2008 Mar;27(3):58, 60, 62-65.

2. Zarb GA, Bolender CL. Prosthodontic treatment for edentulous patients. 12th ed. St Louis: Mosby; 2004. p. 123-159.

3. Sharry JJ. Complete denture prosthodontics. 3rd ed. New York: McGraw-Hill; 1974.

4. Terrell WH. Immediate restorations by complete dentures. J Prosthet Dent 1951;1:495-507.

5. Standard SG. Preparation of casts for immediate dentures. J Prosthet Dent 1958;8:26-30.

6. Nagle RJ, Sears VH, Silverman SI. Denture prosthetics: complete dentures. 2nd ed. St Louis, MO: Mosby; 1962.

7. Rayson JH, Wesley RC. An intermediate denture technique. J Prosthet Dent 1970 Apr; 23(4):456-463.

8. Tadi D, Atluri AD, Kadiyala DR, Suraneni S. Maxillary immediate denture: a case report. Int J Basic Appl Med Sci 2013 May-Aug;3(2):186-189. 